\title{
Indications for use of preformed crowns in pediatric dentistry
}

\author{
Evgeni Dimitrov ${ }^{1}$, Radosveta Andreeva ${ }^{1}$, Milena \\ Georgieva ${ }^{1}$.
}

\author{
1. Department of Pediatric Dentistry, Medical \\ University of Varna;
}

\begin{abstract}
Preformed steel crowns are factory-made structures that are used in the restoration of damaged teeth significantly affected by multi-surface carious lesions. They cover the entire clinical crown, which provides reliable prevention of the occurrence of secondary caries. Placing the conventional steel crowns require some preliminary preparation of the tooth, which may be relatively difficult for the clinician when working with younger patients. Indications for PMCs usage on primary teeth are: prior pulp therapy; need for restorations of multi-surface caries and patients at high caries risk; primary teeth with developmental defects; where an amalgam is likely to fail; fractured teeth; teeth with extensive wear; abutment for space maintainer. However, the use of preformed crowns with minimal invasive treatments, such as the Hall technique, allows for these crowns to be used more often in the everyday practice of children's dentists. They are the most resistant in terms of mechanical strength in time of all obturation materials and should be an option for the restoration of temporary dentition, especially in children with high risk of caries. The Hall technique represents a minimally invasive method to control the carious process, wherein the metal preformed crown is placed directly on carious lesions of deciduous molars, with or without partial removal of carious mass and without any preparation of the affected tooth. Preformed metal crowns are the best method for the management of small to mediumcarious lesions of class II on temporary molars.
\end{abstract}

Keywords: indications, preformed metal crowns, carious lesions

Preformed steel crowns are factory-made structures that are used in the restoration of damaged teeth significantly affected by multi-surface carious lesions. They cover the entire clinical crown, which provides reliable prevention of the occurrence of secondary caries. Placing the conventional steel crowns requires some preliminary preparation of the tooth, which may be relatively difficult for the clinician when working with younger patients. Stainless steel crowns are used on the back teeth and are silver in color. Stainless 
steel crowns with esthetic white coating are used for the front teeth. They are silver in color but have a white coating on the front part of the tooth. There is another treatment option with aesthetic zirconium crowns for primary teeth. The use of aesthetic crowns is a relatively new technology available to pediatric dentistry for the restoration and rehabilitation of the primary dentition. Zirconium crowns are not available on the Bulgarian market.

Indications for PMCs usage on primary teeth:

- $\quad$ Prior pulp therapy $(1,2)$

- $\quad$ For restorations of multi-surface caries and for patients at high caries risk $(1,2,3,4)$

- $\quad$ Primary teeth with developmental defects $(1,2,5,6)$

- Where an amalgam is likely to fail (e.g., proximal box Extended beyond the anatomic line angles) $(7,8,9)$

- $\quad$ Fractured teeth $(1,10,11)$

- $\quad$ Teeth with extensive wear $(1,12)$

- $\quad$ Abutment for space maintainer $(1,2,10,11)$

-

The Hall technique represents a minimally invasive method to control the carious process, wherein the metal preformed crown is placed directly on carious lesions of deciduous molars, with or without partial removal of carious mass and without any preparation of the affected tooth. Initial studies in Scotland have shown that this technique not only surpasses conventional methods of restoration of temporary molars, but is also more highly preferred by clinicians, children and their parents. The method can be a good alternative for children who are unable to tolerate conventional treatment with local anesthesia. However, this technique cannot be applied in all cases and is contraindicated in teeth with symptoms of pulp inflammation (14).

Indications for Hall technique usage (14):

1. Primary molar teeth with moderate decay, but no clinical signs or symptoms of pulpal pathology.

2. Dentitions of children with limited cooperation, who are unable to accept conventional restorative treatment with local anesthesia.

Careful selection of clinical cases is very important for the success of the technique. Preformed metal crowns are the best method for the management of small to medium-carious lesions of class II on temporary molars (fig.1) (13). A comprehensive anamnesis should be taken, as well as bitewingradiographs of the affected teeth. All clinical and paraclinical examinations should exclude pulp pathology, since preformed metal crowns should not be placed on teeth with signs or symptoms of irreversible pulpal involvement. $(13,14)$ The result of treatment is monitored for six months to one year by clinical examination and radiographs. 


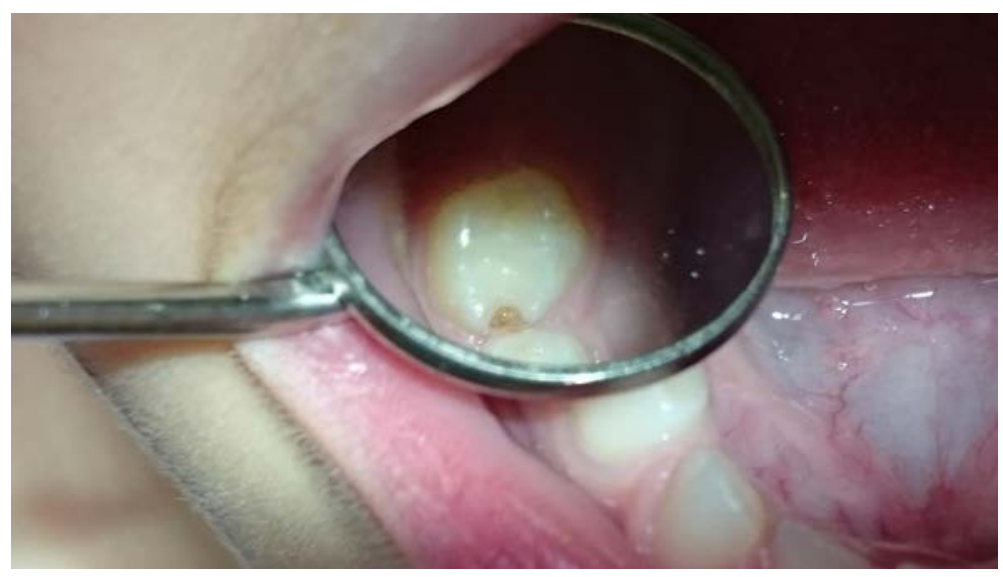

Fig.1 Class II carious lesion on second primary molar

Step 1: Measure size - Different sizes of PMCs are tried on to find one that covers the occlusal surface of the tooth but does not impinge on the teeth on either side, and there is a feeling of 'spring back'. If necessary, orthodontic separators may be placed 3 days prior to fitting the PMC to ease placement. The PMC is not pushed through the contact points. The crown should not be fully seated at this point as it can be very difficult to remove for cementation. If necessary, the length of the crown gingival can be reduced (13)

Step 2: Fill - Fill the PMC with glass-ionomer cement which is mixed with normal creamy consistency as when fixing individually designed crowns. The cement is placed in preformed crown almost to the brim. The cement has to be positioned from the base to the brim of the crown to cover its walls. (13)

Step 3: Locate and seat - Before placing the crown over the tooth some glass-ionomer cement may be wiped on the tooth or placed in any cavitation to help ensure a good seal. The crown is placed evenly over the tooth and engaged in the approximal contact points using finger pressure to secure its position. (fig.2) While using a cotton roll or lignin, the child is asked to clench his/her teeth tightly fitting crown to the tooth. Then it must be carefully checked whether the crown is positioned evenly. If necessary the clinician may fix the crown by strong pressure with their finger. If the PMC fails to fully seat, it should be removed quickly, using a large spoon excavator kept ready for this purpose. (13) 


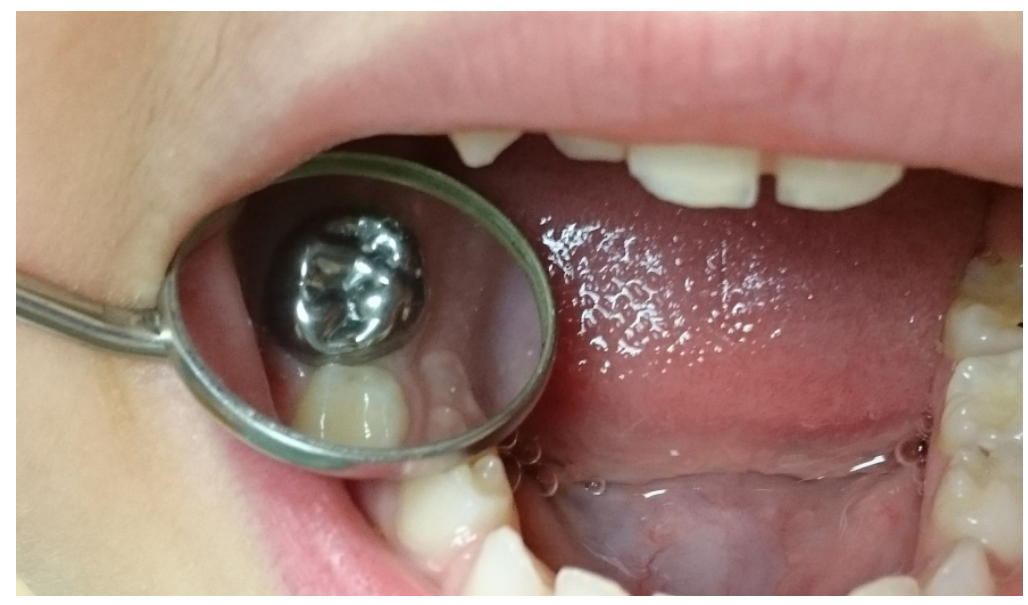

Fig.2 Position of performed metal crown on the second primary molar

Step 4: Wiping the excess cement - Immediately after fixing the crown child is asked to open his mouth to check positioning and remove excess cement while still wet. (13)

Step 5: Seating further - After careful evaluation of the position of the crown even while the cement is still soft, the child is instructed to bite down again with or without cotton (lignin) roll. It is likely that some more glass-ionomer will be extruded. The child should keep pressure on until the cement has set, to prevent the crown from rising back up and possibly compromising the seal. (fig.3) (13)

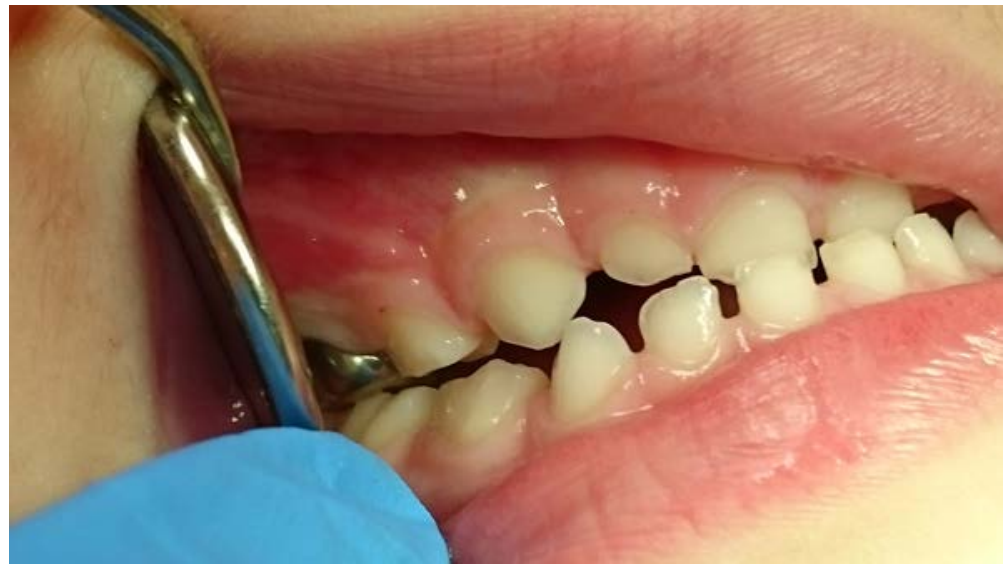

Fig.3 The child is asked to bite down while glass-ionomer cement has indurated

Step 6: Check and clean - Make a final check of the crown and remove any excess cement with hand excavator. Dental floss can be used to remove cement on approximal surfaces. Blanching of gingiva usually disappears within minutes. Minimal occlusal discrepancy is normalized after a few weeks. (fig.4). The child should be praised, and reassured. (13) 


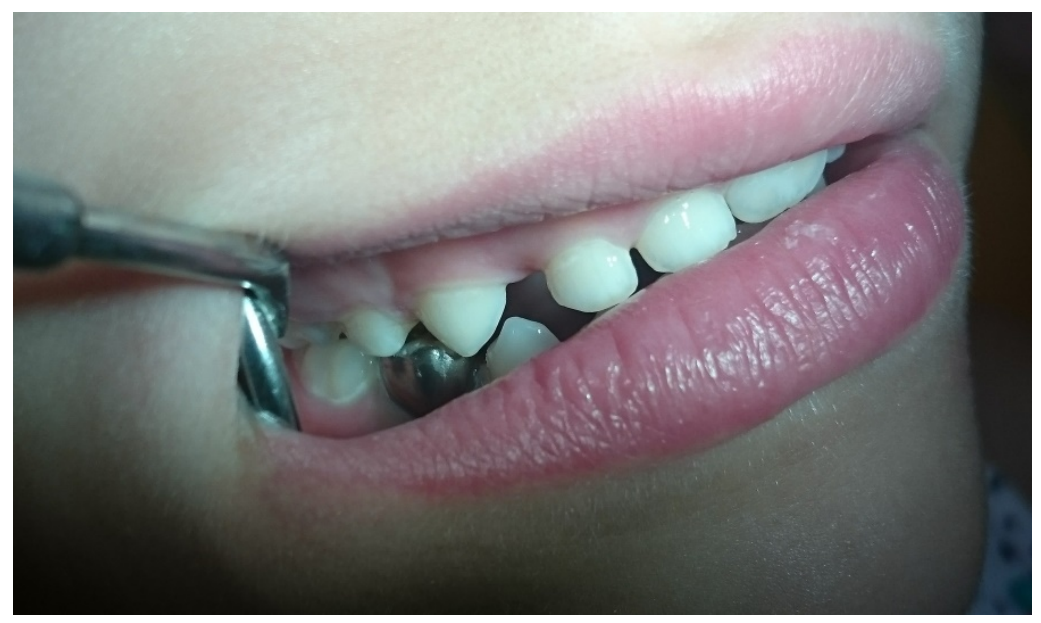

Fig. 4 Minimal occlusal discrepancy after placing the crown

Preformed metal crowns (PMCs) for primary molar teeth were first described in 1950 by Engel (15), followed by Humphrey (16). Since then, design modifications have simplified the fitting procedure and improved the morphology of the crown so that it more accurately duplicates the anatomy of primary molar teeth. The morphology of a primary molar tooth differs significantly from its permanent successor, in part by having its greatest convexity at the cervical third of the crown. Nash4 made the point that carrying out a crown preparation of a tooth solely for use as an abutment is destructive to tooth tissue and that bands are preferable to support appliances to preserve arch space. When both a crown and space maintainer are required, the space maintainer shouldn't be attached to a band cemented over the crown; with this arrangement, subsequent removal of the space maintainer leaves an intact and smooth crown surface. (4) In a recent editorial, Pinkerton (9) suggested that indications for placement of a PMC should include children patients who are unlikely to attend regular recall appointments or who are unlikely to be reliable preventive patients. Duggal (1) listed one exclusion criterion for fitting a primary molar crown, namely an inability to fit one. This encompassed the amount of tooth tissue remaining and the ability of the patient to cooperate with the treatment. It has also been recommended that teeth approaching exfoliation within 6 to 12 months should not be fitted with a PMC. (4)

\section{Conclusion}

In addition, preformed metal crowns with minimal adaptation surpass conventional filling material in almost all aspects: the approval of the young patients, parents and dentists; "small" failures - loss of restoration or any part of it or secondary caries and "large" failures - pain, abscess and premature extraction. (13)

In Bulgaria this method of treatment is not very widely known, because of the price of crowns. The cost of treatment is about 50 euro. In the Faculty of Dental Medicine at the Medical University of Varna, this kind of treatment will be included in the students' curriculum for pediatric dentistry in September 2016. 


\section{References}

1. Duggal MS, Curzon MEJ, Fayle SA, Pollard MA, Robertson AJ. Restorative Techniques in Paediatric Dentistry. 1st ed. London: Martin Dunitz; 1995.

2. Allen WE. Stainless steel: Its use in pedodontics. Dent Clin N Amer. 1966;1:357-363.

3. Myers DR. The restoration of primary molars with stainless steel crowns. ASDC J Dent Child. 1976;43:406-409.

4. Nash DA. The nickel-chromium crown for restoring posterior primary teeth. JADA. 1981; 102:44-49.

5. Mink JR, Bennett IC. The stainless steel crown. J Ont Dent Assoc. 1968; 45:420-430.

6. Goldberg NL. The stainless steel crown in pediatric dentistry. Dent Digest. 1969; 75:351-355.

7. Henderson HZ. Evaluation of the preformed stainless steel crown. ASDC J Dent Child. 1973; 40:353-381.

8. Goto G, Imanishi T, Machida Y. Clinical evaluation of preformed crown for deciduous teeth. Bull Tokyo Dent Coll. 1970; 11:169-176.

9. Pinkerton JR. Editorial. Intraprofessional controversies: reflections on the stainless steel crown. ASDC J Dent Child. 2001; 68:292-293.

10. More FG, Pink TC. The stainless steel crown: A clinical guide. J Mich State Dent Assoc. 1973; 55:237-242.

11. Croll TP. Preformed posterior stainless steel crowns: An update. Compendium. 1999; 20:89104.

12. Duggal MS, Curzon MEJ. Restoration of the broken down primary molar: 2 . Stainless steel crowns. Dent Update. 1989;16: 71-75.

13. Revolutions in Pediatric dentistry - 1st edition, edited by Christian H.Splieth et al. 2011.

14. Handbook of pediatric dentistry - 4th edition, edited by Angus C. Cameron, Richard P. Widmer. 2013.

15. Engel RJ. Chrome steel as used in children's dentistry. Chron Omaha Dist Dent Soc. 1950; 13:255-258.

16. Humphrey WP. Use of chrome steel in children's dentistry. Dental Survey. 1950; 26:945-949. 
Corresponding author:

Milena Todorova Georgieva

Faculty of Dental Medicine,

Medical University of Varna

84 Tzar Osvoboditel Str.

9002 Varna, Bulgaria

Tel.: 0883424786

e-mail: dr.milena.georgieva89@gmail.com 